\section{Entrevista: Dr. Carlile}

Interview: Dr. Carlile
Dr. Carlile Lavor é médico, sanitarista, defensor do Sistema Único de Saúde (SUS), ex-professor da Universidade de Brasília, secretário de Saúde do Estado do Ceará por duas vezes (1987-1988 e 2015). Ele foi responsável pela criação dos agentes de saúde no Ceará em 1987, precursores dos agentes comunitários de saúde da equipe da Estratégia Saúde da Família. Dr. Carlile foi consultor para o Ministério da Saúde de Angola em 2007/2008 e 2014 para planejamento e implementação de programa de agentes de saúde nesse país. Foi também coordenador do escritório da Fundação Oswaldo Cruz no Ceará entre os anos de 2008 e 2014.
Dr. Carlile Lavor is a physician, sanitarian, defender of the Unified Health System (SUS), a former professor at the University of Brasília, and a two-time Secretary of Health of Ceará, Brazil (1987-1988 and 2015). He was responsible for the creation of the health agents in Ceará, in 1987, forerunners of the Family Health Strategy team's community health agents. Dr. Carlile served as a consultant to the Ministry of Health of Angola in 2007/2008 and 2014 in the planning and implementation of the health agent program in that country. He also served as the Fundação Oswaldo Cruz office coordinator in Ceará from 2008 to 2014. 


\section{Revista}

Doutor Carlile, o senhor poderia falar da sua trajetória de vida, fazendo um link com a história da atenção primária à saúde, de medicina comunitária, dos agentes comunitários de saúde? Mais especificamente, o senhor poderia falar sobre a criação dos agentes de saúde no estado do Ceará, protagonismo seu em uma época importante para nossa história?

\section{Dr. Carlile}

Eu me formei numa época em que a medicina passava por grandes transformações. Foi a época em que se evidenciaram fatores que levavam ao câncer, por exemplo; que o fumo provocava o câncer. No início da década de 1960 foi publicado um trabalho de acompanhamento dos médicos ingleses: quem fumava, quantos cigarros fumava e a incidência de câncer; então, isso foi uma grande mudança da medicina. Em uma doença como o câncer, passou a ser possível conhecer suas causas para realizar a prevenção. Isso também ocorreu em relação às doenças do coração, a experiência mostrou que era possível reconhecer os fatores que levavam às coronariopatias: falta de atividade física, colesterol e pressão altos. Isso provocou uma mudança muito grande, porque antes só se sabia da prevenção das doenças infecciosas, das vacinas e da transmissão dessas doenças, doenças que há séculos faziam medo à sociedade; e aí se aprendeu a prevenir por meio de vacinas ou, digamos, do isolamento. Identificou-se que a hanseníase era transmissível; então, se o doente fosse isolado, se evitava que outra pessoa fosse contaminada. Logo, a medicina, ao passar só das infecções para as doenças crônicas, deu um grande passo no sentido da prevenção das doenças. Foi naquele momento que se criou no Ceará o Instituto de Medicina Preventiva, baseado nessa coisa nova que estava surgindo, e a Organização Pan-Americana de Saúde (OPAS) estimulou muito as faculdades de medicina a adotarem essa estratégia.

\section{Revista}

De que década nós estamos falando?

\section{Dr. Carlile}

Final da década de 1950 e início da década de 1960. Então, a OPAS estimulou muito as faculdades de medicina a trabalharem a prevenção das doenças, o que permitiu se dar mais importân- cia ao papel da comunidade. Enquanto a doença antes era essencialmente hospitalar, passou-se a ver que a comunidade ia ser um grande local de estudos e de pesquisas e de prevenção das doenças. Assim, originou-se no Ceará o Instituto de Medicina Preventiva e no mundo todo se caminhou para a chamada medicina comunitária. Eu fui bolsista do Instituto de Medicina Preventiva e, claro, me dediquei muito a esse tema, e representei inclusive os estudantes de medicina na mudança do currículo da Faculdade de Medicina do Ceará quando se caminhou para ser oferecida a medicina preventiva do primeiro ano até o sexto. Na reforma do currículo, eu representei os estudantes nessa discussão com os professores. Antes se começava com antropologia no primeiro ano, estatística no segundo ano, epidemiologia no terceiro e até chegar administração em saúde no sexto ano. Foi isso, eu vivi muito de perto e pude então me dedicar, me aprofundar nesse tema. Fiz microbiologia. Dentro do estudo de medicina preventiva houve um estímulo para que estudantes se dedicassem às chamadas cadeiras básicas, e eu escolhi microbiologia e Imunologia, e por isso fiz microbiologia como especialização. Ainda aqui no Ceará, trabalhei no Instituto de Medicina Preventiva, logo depois de formado, e também no Hospital de Tuberculose de Maracanaú. Depois fui para Brasília, e lá pude viver a grande experiência de uma Faculdade de Medicina que vivia como uma pequena comunidade. No Ceará, a prática do Instituto de Medicina Preventiva era realizada no distrito de Porangabussu, onde já falávamos em integração docente assistencial e um centro de saúde que cuidava da população local. Fui ver isso com muito mais intensidade em Brasília, quando a Faculdade de Medicina escolheu a cidade de Sobradinho para estudar com profundidade a atenção à saúde daquela população. Era toda uma Faculdade de Medicina dedicada a uma população de 25 mil habitantes. E, no ensino, assumi a responsabilidade de oferecer a primeira disciplina quando os alunos entravam na Faculdade de Medicina, e depois que saíam do ciclo básico, e que se chamava 'Mecanismos de Agressão e Defesa'. Estudava-se como era a relação do indivíduo com seu ambiente, que tipo de agressões ele recebia, agressões biológicas, físicas, químicas ou sociais; e como é que o organismo se defendia disso. E depois pudemos desenvolver atividades práticas em uma outra 
cidade chamada Planaltina - um trabalho conjunto entre Universidade-Secretaria de Saúde e Ação Social do Distrito Federal; uma experiência com os agentes de saúde. Lá tive a sorte de ter como colega o professor Frederico Samuel Barbosa, que tinha também uma grande experiência de trabalho com a comunidade. A experiência inicial dele foi com esquistossomose, depois trabalhou na Organização Mundial de Saúde em Genebra e pôde visitar também países da Europa, África e Ásia. Visitou ainda a China, como o doutor Alencar, que era do Instituto de Medicina Preventiva, e também viveu a experiência chinesa da revolução. A China teve uma experiência maior porque, com a revolução chinesa, em 1949, foi desenvolvido um movimento para que a própria comunidade melhorasse seus indicadores de saúde: controle da esquistossomose, calazar, das verminoses e o controle das moscas; então, foi uma grande experiência com a participação da população.

\section{Revista}

Essa sua experiência em Brasília foi no final da década de 1960 ou já estamos no começo da década de 1970?

\section{Dr. Carlile}

Década de 1970. Eu fiquei em Brasília de 1969 a 1978. Volto ao Ceará em 1979, já como sanitarista da região de Iguatu. Volto para o Ceará depois de ter vivido a experiência de Planaltina, com o trabalho do agente comunitário de saúde, não com esse nome, nós chamávamos auxiliar de saúde.

\section{Revista}

Mas, então, foi em Planaltina a primeira experiência com os agentes, que hoje conhecemos como agente comunitário de saúde?

\section{Dr. Carlile}

Isso mesmo. Brasília é dividida em cidades satélites e a cidade satélite da Faculdade de Medicina era Sobradinho, e a cidade que a gente fez a experiência com os agentes de saúde foi Planaltina, cidade vizinha que é muito mais rural e com menos serviços de saúde. Lá havia a vantagem de existir um bom centro de saúde, e seu diretor era um sanitarista com grande experiência, e a Mirian [esposa do Dr. Carlile] dirigia o serviço social da região. Mirian já tinha acumulado uma experiência muito grande trabalhando com essa população. Começamos esse trabalho em Planaltina e em 1975 fizemos a seleção e a formação dos agentes. Entre 1976 e 1978 tivemos a experiência com os agentes. Foram dois anos avaliando os resultados importantes e, quando voltamos ao Ceará, trouxemos toda essa experiência acumulada, de como é que se formava o agente de saúde, o que ele era capaz de fazer, que doenças ele poderia evitar, e aí fizemos no Ceará uma adaptação, porque uma coisa era a infraestrutura na Universidade em Brasília, com todas as condições ideais para se trabalhar, e outra coisa é você estar no interior do estado do Ceará da época, com condições de assistência precaríssimas, população muito pobre e sem recursos, sem hospital. No entanto, foi uma adaptação importante para saber se seria possível adaptar a experiência da universidade para o sertão - isso foi feito entre 1979 e 1986. Eu e a Mirian, sanitaristas da regional de Iguatu que compreendia 14 municípios.

Essa experiência nos fez conhecer muito bem o que era o sistema de saúde do Ceará, tanto público - Secretaria de Saúde - como privado, principalmente no interior do estado. E, como trabalhamos com 14 municípios diferentes, sabíamos como os médicos trabalhavam, os hospitais, os centros de saúde, como era a atenção à saúde e os problemas sociais e econômicos, a pobreza, o sertão, as dificuldades de água, alimentação, a renda, a política etc. Foi uma experiência especial. Foi com base nela que o governador eleito, Tasso Jereissati, me chamou para assumir a Secretaria de Saúde do Ceará. Tínhamos uma experiência grande, eu era praticamente o único médico trabalhando em dedicação integral no setor público. Havia acumulado um conhecimento interessante nesse período, e foi fácil pensar um sistema novo de saúde com as condições econômicas que existiam na época. O Ceará era muito pobre, e uma das coisas possíveis de ser feita era trabalhar com os indicadores da mortalidade infantil. O Ceará apresentava uma taxa de mortalidade infantil que equivalia à da África de hoje, ou seja, mais de cem óbitos de crianças a cada mil que nasciam. Uma vergonha! Era possível melhorar isso, reduzir essa mortalidade infantil. E foi nessa perspectiva que começamos o trabalho dos agentes de saúde. Colocamos, em 1987, seis mil mulheres para trabalhar com a gente em uma coisa muito simples: 
trazer a mãe para o pré-natal, conseguir que o parto fosse em uma área assistida - ter um hospital onde a mãe pudesse ter seu filho - e acompanhar o desenvolvimento daquela criança, o peso, a higiene, a vacinação. Assim, se conseguiu reduzir muito a mortalidade infantil com um mínimo de recursos, mostrando que era possível melhorar a saúde. Por que escolhemos crianças? Porque era área onde se tinha muito bem estabelecidos os fatores que levavam à redução da mortalidade, e na criança a gente sabia muito bem que o soro oral tinha um resultado especial, que as vacinas tinham o seu valor muito bem estabelecido; o governo brasileiro já tinha condições de ter a vacina e uma das coisas que se fez foi melhorar sua rede de distribuição e de conservação. E treinar vacinadores e estender a rede de centros de saúde foi relativamente barato, coisas que tínhamos condições de fazer.

\section{Revista}

O senhor me disse um tempo atrás que parte dos recursos importantes para essas primeiras seis mil mulheres veio do dinheiro da seca, se é que eu posso chamar assim.

\section{Dr. Carlile}

Claro.

\section{Revista}

O senhor pode falar um pouco mais sobre esse assunto?

\section{Dr. Carlile}

Normalmente, durante a seca, o governo federal mandava recursos para os estados para que as pessoas sobrevivessem à seca, à fome. A maior parte da população vivia da agricultura, e com a seca não tinha o que comer nem tinha trabalho. Então, o governo federal, tradicionalmente, mandava recursos para que os estados oferecessem trabalho para as pessoas ou distribuíssem comida, ou qualquer outra atividade voltada para amenizar os efeitos da seca. Naquela época, o governo do Estado achou que o mais importante era que cada pessoa recebesse um salário mínimo e não um pouquinho, como muitas vezes se fazia, mas que de fato se desse um trabalho, e pediu a cada secretaria que organizasse a atividade. $\mathrm{Na}$ área da saúde eu disse que queria empregar seis mil mulheres. Normalmente se empregavam homens; entretanto, muitas fa- mílias só tinham mulheres com condições de trabalho. Então contratamos as mulheres como agentes de saúde.

\section{Revista}

Cada mulher dessas era responsável por quantas pessoas?

\section{Dr. Carlile}

Cem famílias.

\section{Revista}

Como é que o senhor vê a interiorização do cuidado naquela época e hoje? O que mudou do início?

\section{Dr. Carlile}

Um aspecto importante ligado aos agentes de saúde foi a interiorização dos enfermeiros. Em 1987, tínhamos cerca de cinquenta enfermeiros para os 184 municípios do estado. Para implantar o programa dos agentes de saúde, pedimos aos municípios que contratassem enfermeiros, o que possibilitou a interiorização do enfermeiro. Esse profissional era importante porque queríamos garantir vacinas e pré-natal no interior. Então, uma das contribuições do município para ter os agentes de saúde era ter um enfermeiro - este foi um grande avanço! Colocamos a média de um enfermeiro (40h) para cada quarenta agentes. Entre 1987 e 1988 fui secretário do Estado e em 1989 assumi a Secretaria de Saúde de Iguatu; foi quando criamos, no período da municipalização, o Conselho Estadual de Secretários Municipais de Saúde; e nessa municipalização uma das coisas essenciais era estender a atenção básica e ter o enfermeiro distribuído em larga escala, junto com os agentes de saúde e médicos para fazer o atendimento básico. Começamos por Iguatu, e se estendeu praticamente para todo o estado, quase todos os municípios passaram a ter secretarias municipais de saúde que se dedicavam à atenção básica. Em 1993, Odorico Monteiro assumiu a Secretaria de Saúde de Quixadá e viu a importância de contratar médicos. Lá em Iguatu mesmo, tínhamos uma enfermeira morando em cada distrito, mas o médico ia uma a duas vezes por semana. Naquele mesmo ano em Quixadá o Odorico lançou a ideia de que ao lado do enfermeiro houvesse também um médico, e foi quando se originou o Programa Saúde da Família. Paralelamente estava acontecendo a experiência 
do médico de família do modelo cubano em Niterói. Juntou-se também a experiência do Hospital Conceição de Porto Alegre e a formação de médico de família, e, em dezembro de 1993, o Ministério da Saúde (MS) criou o Programa Saúde da Família. Em 1991 o MS já tinha estendido o programa do agente de saúde do Ceará para todo o Nordeste e, em 1994, estendeu o programa do agente de saúde para todo o Brasil e criou o Programa Saúde da Família. O Ceará partiu na frente com muita intensidade e rapidamente passou a ter muitas equipes de saúde da família. Posteriormente, esse processo se espalhou pelo Nordeste e pelo Brasil todo.

\section{Revista}

Pelo que entendi, o senhor acredita que parte do sucesso dos agentes comunitários e do Programa Saúde da Família tem a ver com essa interiorização do cuidado da saúde. Voltando a essa temática, interiorização do cuidado, o senhor acredita que ela veio na hora certa? Poderia ou deveria ter sido feita de forma diferente?

\section{Dr. Carlile}

O agente de saúde foi um grande intermediário entre o Estado e a população. Foi o profissional que chegou mais perto da população, nos distritos mais remotos, áreas rurais mais afastadas. Chegou uma pessoa representando o governo do Estado, representando o Estado brasileiro; foi uma figura nova. Um fato interessante é que o agente recebia um salário mínimo, que naquela época, no interior de um estado pobre como o Ceará, era muita coisa. Na época, uma professora primária da área rural ganhava cerca de um quinto do salário mínimo. Então as mulheres primeiras agentes de saúde, com pouca instrução formal, ganhando um salário mínimo - eram uma novidade muito grande. Elas faziam um trabalho da maior importância: levar os conhecimentos essenciais de saúde à população. $\mathrm{O}$ agente de saúde deu uma contribuição muito importante, e com sua implementação trouxe a necessidade de organização do serviço. Você contava com um enfermeiro que começava a sentir o que era a organização do sistema de saúde, a atenção à criança e começava a perceber outros problemas; aí os municípios começaram a ver a necessidade do médico.

Havia começado, a partir de 1989 e com a municipalização da saúde, o repasse de mais recursos para a atenção básica. Os municípios passaram a se organizar e a entender um pouco mais sobre as características do atendimento básico. Em 1989, como vice-presidente do Conasems [Conselho Nacional de Secretarias Municipais de Saúde], participei de reuniões com os secretários municipais de saúde de todo o Brasil. Trabalhamos muito nesse processo de municipalização da saúde, possibilitando o crescimento vertiginoso da atenção básica, com resultados importantes na redução da mortalidade infantil. Esse processo não ocorreu somente no Nordeste ou na área rural; as grandes cidades com as suas favelas também começaram a ter esse atendimento básico. Foi um crescimento nacional, e nosso país apareceu nos anos seguintes como campeão mundial de imunização, campeão mundial de redução de mortalidade infantil, aumento do atendimento a pacientes com diabete, hipertensão etc. Começaram então a aparecer publicações internacionais mostrando que o Brasil avançava na atenção primária.

\section{Revista}

Dr. Carlile, qual é a sua avaliação sobre as equipes de saúde da família de hoje? O que mudou? O que o senhor acha que ainda precisa melhorar?

\section{Dr. Carlile}

Tinha havido um grande movimento de interiorização e de seleção de equipes, mas faltou uma coisa essencial, que é o aprofundamento dos conhecimentos para avançar na atenção primária. No final da década de 1980 e início da década de 1990 e, hoje, 25 anos depois, a medicina evoluiu muito, mas na atenção especializada. O Brasil estacionou na discussão sobre a atenção básica; durante o governo militar, os especialistas dedicados a esse tema ficaram estudando nas universidades, e, somente na virada da década de 1980 para a de 1990 esse processo foi retomado; no entanto, embora de forma incipiente, como o Rio Grande do Sul, que se concentrou no estudo da atenção básica. Significa que hoje praticamos uma atenção básica de trinta anos atrás, daí nosso interesse na Fiocruz Ceará de voltar a estudar a atenção básica, porque do mesmo jeito que a medicina especializada, hospitalar avança dia a dia com grande espaço e com bons resultados, a atenção básica não evoluiu. Criou-se um descompasso muito grande; uma 
medicina superavançada, com cada vez mais tecnologias e uma medicina atrasada, parada no tempo. Então, você tem hoje, digamos no mundo todo, médicos que realizam residência de pelo menos três anos. No Ceará temos esses médicos saindo da faculdade de medicina sem uma formação, sem uma especialização, provocando um atendimento de baixa qualida-de na atenção básica - já que esses médicos são absorvidos pela Estratégia Saúde da Família.

\section{Revista}

O senhor teve duas grandes experiências em Angola. O senhor me disse uma vez que achava interessante como os angolanos se aproveitavam bem das experiências dos cubanos. Quais são, no seu ponto de vista, as diferenças e as semelhanças entre o Brasil e Angola nesse aproveitamento dos cubanos? E o que o senhor acha do modelo cubano?

\section{Dr. Carlile}

Cuba considera a área da saúde como um dos pilares de sustentação do governo. É o médico que está em todas as comunidades, assim como os agentes de saúde. Lá você tem um médico em cada cem ou 120 famílias, você tem um médico que conhece muito bem todas as famílias. A área da saúde teve prioridade especial desde o presidente Fidel Castro; não só por ser um dos sustentáculos do seu governo, mas porque ele viu resultados positivos. Cuba, embora ainda seja pobre, realmente um país com grandes dificuldades econômicas, tem um grande resultado na saúde. Hoje o sistema de saúde tem alta resolubilidade, você tem um dos melhores resultados de saúde do mundo em termos de mortalidade infantil, esperança de vida; mesmo com poucos recursos, eles conseguem um super-resultado. Agora, comparando Angola com o Brasil. Angola tem uma responsabilidade e uma autonomia muito grande de governo. Eles passaram pela guerra e dependeram do governo português até cinquenta anos atrás; então, a ideia de autonomia que eles têm é muito forte, não aceitam qualquer coisa que venha de fora. Eles querem aprender e têm relações com o mundo todo (e.g. China, Vietnã, Cuba, Estados Unidos, França), mas com uma noção muito clara do que é deles, o que é bom para eles. Os angolanos têm uma relação muito estreita com Cuba. Na época da guerra, Cuba participou dela ao lado dos que venceram e atualmente estão no poder. Até há pouco tempo, Angola tinha apenas uma faculdade de medicina, localizada na capital. Hoje, em cada uma das cinco regiões do Estado, foram criadas faculdades de medicina, e os cubanos são muito importantes para o desenvolvimento dessas faculdades, além de usarem médicos cubanos para o atendimento básico ou para o atendimento secundário nos hospitais regionais. O que vejo no Brasil foi uma coisa muito ruim. Colocaram-se os médicos cubanos como sendo melhores do que os médicos brasileiros, isso para mim foi a pior coisa que aconteceu nesse programa do Mais Médicos, o que criou toda uma reação por parte dos médicos brasileiros. Criou uma reação negativa, e está dificultando o melhor aproveitamento dos médicos cubanos. Fui a Cuba em 1998 para ver se conseguia trazer professores cubanos para auxiliar na formação dos nossos médicos de família, onde eles têm uma grande experiência, mas infelizmente não consegui bons resultados. Eu acho que eles poderiam nos ajudar muito a formar os médicos de família, onde temos uma deficiência muito grande. As nossas faculdades de medicina não têm ou têm muito poucos professores de Medicina de Família; então, seria importante trazer médicos cubanos, que não precisavam ter licenciamento junto ao CRM como médico, eles não precisariam fazer a medicina assistencial, mas apenas ser professores dos médicos na área especifica de atenção primária, e poderiam dar uma grande contribuição. Enfim, infelizmente não aconteceu.

\section{Revista}

O senhor acha que uma das diferenças é que em Angola os cubanos vão não só para fazer, mas também para ajudar a formar, e aqui no Brasil eles estão apenas fazendo assistência?

\section{Dr. Carlile}

Vão direto para assistência, né?

\section{Revista}

Uma vez o senhor me falou que a ESF precisava investir no eixo de formação de qualidade. Na sua perspectiva, se é que eu posso colocar dessa forma, quais os maiores equívocos, na atual política de saúde da família? É essa falta de estudo que o senhor mencionou anteriormente? Falta base científica para o que está sendo feito? Será que as ações estão sendo realizadas sem terem sido planejadas? É isso? 


\section{Dr. Carlile}

Estamos trabalhando um modelo de saúde da Família que foi pensado 25 anos atrás e que foi muito bom, mas que ficou parado no tempo. Então, temos que formar melhor o médico, formar melhor o enfermeiro, formar melhor o agente de saúde. Esses profissionais estão formados para uma realidade de 25 anos atrás, e o mundo hoje é completamente diferente. Se nós já reduzimos a mortalidade infantil, quais são os grandes problemas hoje? É a hipertensão, é o diabetes, é o acidente vascular cerebral, é o câncer, é o abuso de drogas, é a violência. O agente de saúde precisa estar preparado para isso, além dos médicos e enfermeiros. Então, muita coisa que poderia ser feita hoje pela equipe de Saúde da Família não o é; em parte porque não estão preparados para fazer. Ainda temos hoje muitos doentes que morrem na UTI e que poderiam ter sido mais bem tratados e recebido os cuidados paliativos em casa, mas para isso seria necessário ter um médico, um enfermeiro que soubesse fazer isso, e um agente de saúde preparado para apoiar.

\section{Revista}

O senhor disse uma vez, e acho que tem a ver com o que está comentando agora, que os agentes comunitários estagnaram. Explique um pouco mais essa estagnação.

\section{Dr. Carlile}

Exatamente isso. Porque eles foram formados para trazer a mãe grávida até a unidade de saúde, a fim de fazer o pré-natal e acompanhar cada criança. Isso eles fizeram, mas hoje não é mais o maior problema. O maior problema é detectar a hipertensão, o diabetes, ver a obesidade, ver a alimentação, ver a atividade física, ver o hábito de fumar, tabagismo e o abuso de drogas etc. Temos uma epidemia de abuso de drogas que se disseminou em todo o Brasil de maneira impressionante, mas a gente não dá a menor atenção, como se a saúde não tivesse nada a ver com isso. Os nossos adolescentes estão se perdendo com o abuso de drogas; é o crack, é a cocaína, é o álcool, e as nossas equipes de saúde agem como se isso não tivesse a ver com elas, mostrando não estarem preparadas. Então, nós temos hoje um exército de agentes de saúde, 15 mil no Ceará, 250 mil em todo o Brasil, sem saber o que fazer. Conhecem as pessoas que abusam da droga, conhecem os traficantes, conhe- cem o motoqueiro que bebe álcool e sai dirigindo a moto e vai se acidentar, mas não sabem fazer nada com isso.

\section{Revista}

Dr. Carlile, e para o futuro, quais são suas perspectivas? Tanto na Secretaria de Saúde do Estado do Ceará como pessoais. Tive o prazer de conviver um tempo com o senhor no seu tempo de Fiocruz Ceará. Sempre senti uma sensibilidade grande para aquele que foi chamado de desaventurado no sentido que não tem acesso à saúde, que não tem acesso à renda, que não tem mais esperança. Eu queria que, por um lado, o senhor me dissesse quais são as suas perspectivas para o futuro e, por outro, o que o move.

\section{Dr. Carlile}

Olha, uma das coisas importantes que a gente vê é que hoje nós temos muito mais recursos financeiros do que há vinte, trinta anos. O orçamento do SUS no Ceará foi de R\$ 6,8 milhões em 2014 ah, mas está longe de ser o dinheiro americano, alemão ou inglês, mas para o Ceará é muito dinheiro. Você tem quase 800 reais per capita/ano para o sistema de saúde; se for bem aplicado, pode gerar muito dinheiro. Seria para aplicar em hospital? Uma das primeiras coisas que estamos conseguindo neste ano é reduzir os acidentes de trânsito. Em conjunto com o município de Fortaleza, por uma ação da Secretaria das Cidades (Dr. Ivo Gomes) e Detran, mostramos que os dias de sábado e domingos são os que têm o maior número de acidentes de trânsito. Eles estão fazendo um trabalho específico em Fortaleza com frequentes blitze para reduzir a quantidade de motoqueiros que dirigem embriagados. Isso tem reduzido pela metade os acidentes de trânsito. Estamos mostrando que é possível fazer muita coisa com poucos recursos financeiros, e o que se gasta em blitz nem se compara com o que se gasta em ter que tratar aquele doente que se acidenta e vai para o hospital. Essa situação não ocorre somente em Fortaleza; todos os hospitais do interior estão lotados com pessoas acidentadas. Provamos que é possível fazer alguma coisa com poucos recursos financeiros, e é para isso que tenho chamado a atenção. Outro trabalho muito importante é o que estamos desenvolvendo com a vice-governadora, chamado O Ceará Pacífico. Como trabalhar de maneira intersetorial para atender aos mais pobres de Fortaleza, 
aquelas regiões mais complicadas com maior violência, com maior abuso de drogas, com as ruas mais sujas, com a maior quantidade de lixo. Três áreas já são foco dessas ações desde o ano passado pela Secretaria de Segurança, onde a polícia realiza trabalho comunitário junto às famílias, junto às escolas, de combate à droga. A Secretaria de Estado está coordenando uma campanha contra as drogas e o município também está trabalhando junto. Vamos trabalhar com os agentes de saúde, os agentes de endemias e a infraestrutura para colocar iluminação melhor nas ruas, limpar a cidade, calçar aquelas ruas para que a cidade volte a respirar como cidade e até os próprios profissionais de saúde possam entrar naquelas áreas que têm medo de entrar. Acredito que é possível chegar até essa população, não tanto por causa da pobreza, porque hoje as pessoas têm uma renda mínima, mas é pela falta de esperança, a falta de perspectiva, é você ter a criança fora da escola. Hoje existem em Fortaleza 1.800 adolescentes apreendidos porque praticaram crimes, mas em situações horríveis, num lugar onde caberia cinquenta existem duzentos. Ao invés de melhorarem, pioram a sua capacidade criminosa. Precisamos resolver essa situação. Nós temos 2.700 agentes de saúde em Fortaleza que, se realmente estiverem integrados às equipes de Saúde da Família, aos enfermeiros, aos médicos, a todos do NASF, acredito que poderemos melhorar a situação. Gastamos muito hoje nos hospitais de Fortaleza, e as pessoas são atendidas nos corredores. Se pudermos garantir médicos nas 22 regiões de saúde do estado, fazendo clínica médica, pediatria, ginecologia e obstetrícia, psiquiatria, teremos um atendimento médico muito melhor e para todos os cearenses. Essa que é a minha grande preocupação hoje: como chegar com os cuidados básicos de saúde a toda a população cearense? Estamos discutindo não só para o Ceará como também para o Brasil, quer dizer, como melhorar a assistência à saúde no Brasil? Uma das coisas que o governador me falou é que a saúde era a área mais mal avaliada hoje no estado, e depois vem a segurança; a gente sabe disso, é muito ruim mesmo. Você vai a um hospital e vê a situação precária entre as pessoas, o medo delas de terem que precisar do hospital e saber que vão enfrentar fila, não só no SUS, mas também nos planos de saúde. Porque se você tem uma criança e vai a um plano de saúde, também vai entrar na fila para ser atendido. Hoje observo um medo grande nas pessoas de adoecer, de precisar de assistência. Então se cria uma 'neurose' nas pessoas poxa, se eu adoecer, para onde é que eu vou? Como é que eu vou fazer? E aí elas se obrigam a fazer plano de saúde sem poder, pagam um mês, dois e não podem mais pagar, perdem o plano. Então, eu acredito que, com esses recursos que a gente possui é possível ter um sistema de saúde razoável, e aí a sociedade poderá começar a acreditar no seu sistema de saúde e começar a investir mais, porque, na hora que todos acreditarem que o sistema de saúde funciona, teremos mais vontade de investir mais, e gradativamente ele vai melhorando ainda mais.

Entrevista concedida à Anya Pimentel Gomes Fernandes Vieira-Meyer, pesquisadora do Escritório da Fundação Oswaldo Cruz no Ceará, em abril de 2015.

El Dr. Carlile Lavor es médico, sanitarista, defensor del Sistema Único de Salud (SUS), ex-profesor de la Universidad de Brasilia, secretario de Salud del Estado de Ceará en dos oportunidades (1987-1988 e 2015). Fue responsable de la creación de los agentes de salud en Ceará en 1987, precursores de los agentes comunitarios de salud (ACS) del equipo de Estrategia Salud de la Familia. El Dr. Lavor fue consultor para el Ministerio de Salud de Angola en 2007/2008 y 2014 en el área de planificación e implementación del programa de agentes de salud en ese país. También fue coordinador de la oficina de la Fiocruz en Ceará entre los años 2008 y 2014. 